\title{
Radio-Histological Correlations of Parotid Tumors
}

\author{
$\mathrm{Z} \mathrm{Alj}^{1 *}$, M Ridal $^{1,2}$, N Benmansour $^{1,2}$, A Taleaun $^{1}$, A Oudidi $^{1,2}$, Z Zaki $^{1,2}$ and MN Alami ${ }^{1,2}$ \\ ${ }^{1}$ Department of otorhinolaryngology, University Hospital Hassan II, Morocco \\ ${ }^{2}$ Faculty of Medicine and Pharmacy, University Sidi Mohamed Ben Abdellah, Morocco \\ *Corresponding author: Alj Zineb, Department of otorhinolaryngology, University Hospital Hassan II, Morocco
}

\section{ARTICLE INFO}

Received: 幽 April 29, 2020

Published: May 12, 2020

Citation: Z Alj, M Ridal, N Benmansour, A Taleaun, A Oudidi, Z Zaki, MN Alami. RadioHistological Correlations of Parotid Tumors. Biomed J Sci \& Tech Res 27(4)-2020. BJSTR. MS.ID.004525.

Keywords: Parotid; Correlation; MRI; Histopathology

\begin{abstract}
The magnetic resonance imaging (MRI) plays a key role in the diagnosis and characterization of parotid tumors. It provides the clinician with anatomical information on the nature of the tumor being investigated. We have analyzed, through 46 cases, the radio-histological correlations of parotid tumors. our study includes 21 men and 25 women. The average age of our patients was 39 years. The most common histological types are pleomorphic adenoma (20 cases), cystadenolymphoma ( 7 cases) and cancers ( 9 cases). For our 46 patients, 39 MRIs and 20 CT scans were performed. The objective of this work is to study the MRI characteristics of parotid tumors correlated with surgical histopathology (parotidectomy) and describe the typical imaging aspects of the main parotid tumors which helps to choose the adequate surgical management of these lesions and to provide the patient with the most accurate information adapted as much as possible to his pathology.
\end{abstract}

\section{Short Communication}

The salivary gland tumor pathology remains relatively rare, representing 3 to $4 \%$ of all tumors of the head and neck. Parotid localization is predominant. It is characterized by a great morphological and histological diversity, but it is the benign forms which predominate especially the pleomorphic adenoma [1]. The most frequent mode of revelation is a cervical swelling of the parotid space. Complementary examinations, in this case imagery, have become real diagnostic tools, on the one hand, to specify the exact location of the lesion, its extension to adjacent tissues and, on the other hand, to predict the malignant or benign nature of the lesion. Ultrasound, whether or not combined with fine needle aspiration, CT and MRI are the most frequently used methods. The objective of this work is to study the MRI characteristics of parotid tumors correlated with surgical histopathology (parotidectomy) and describe the typical imaging aspects of the main parotid tumors.

\section{Materials and Methods}

This is a retrospective study of 46 patients who were followed up and treated for a parotid tumor. The cases were collected over a period of 4 years, from January 2016 to July 2019, at the ENT surgery department at the Hassan II FES University Hospital. We only retained the files containing a computed tomography (CT) and / or magnetic resonance imaging (MRI) and whose nature of the tumor was confirmed by a histological study after parotid surgery. The parameters studied were the patient's age and sex, the motif of consultation. All of the clinical features of the swelling were studied and correlated with histology data. As for the imaging data, for each diagnostic method, we correlated the report of the radiologists concerning the nature of the tumor, to the results of the final histology, and we calculated the sensitivity, the specificity and the diagnostic efficiency of each diagnostic method. All our patients underwent surgical treatment on the tumor with or without associated lymph node surgery. MRI diagnostic values, sensitivity and specificity were calculated for three types of parotid lesions: pleomorphic adenoma, Warthin's cystadenolymphoma, and malignant tumors.

\section{Results}

The gender distribution was almost equivalent, with 25 women (54\%) and 21 men (46\%). The average age was around 39 years with extremes of 7 years and 87 years. All our patients presented a common symptomatology which is the parotid swelling with a size variation between 2 and $4 \mathrm{~cm}(2<$ size $\leq 4)$ in 18 cases or $39 \%$ and between 4 and 6 in 19 cases or $42 \%$. 26 of our patients have swelling 
on the right side (56\%). Among our 46 patients, 16 presented parotid pains, 4 a facial paralysis and four patients a reflex otalgia. At the time of diagnosis, five of our patients presented a cervical lymph nodes. Examination of the stenon canal was normal in all of our patients. The anatomopathological study was mainly carried out on the operative piece, since the extemporaneous examination could only be carried out for a few patients due to technical constraints.

Benign tumors account for $80 \%$ of all of our patients, dominated mainly by pleomorphic adenoma followed by whartin tumor
There were 8 cases of cancer that were of a diverse nature (Table 1). Cervical ultrasound was performed in 18 patients. Computed tomography in 20 patients ( $44 \%$ of the cases), generally in the face of very large tumors initially in order to specify their depth extension. Magnetic resonance imaging was realized for 39 patients (Figures $1 \& 2$ ). We studied the morphological and functional MRI criterias of the pleomorphic adenomas of our patients, warthin tumors and malignant tumors, then we established different criterias associations and their predictability of the final histological result of the tumor.

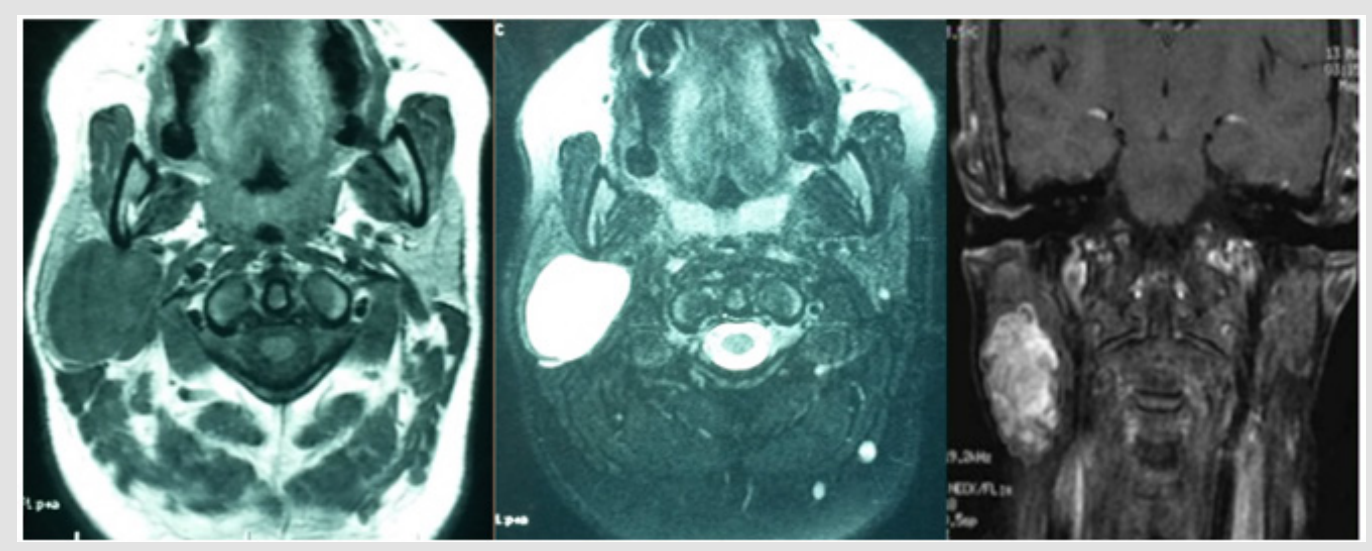

Figure 1: MRI image in axial section in T1, T2, T1C + weighted sequences of a pleomorphic adenoma of the parotid.

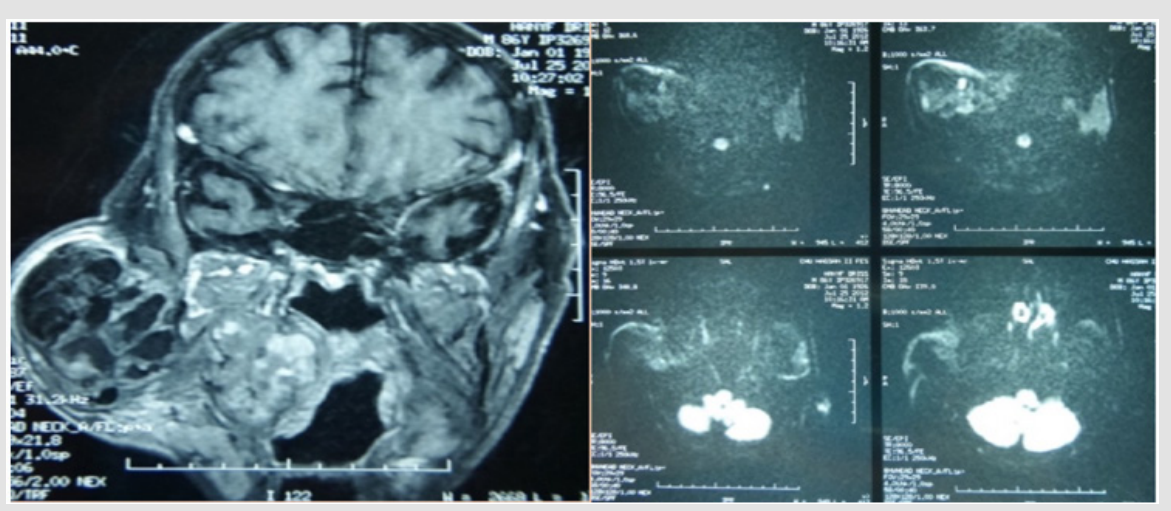

Figure 2: MRI image in axial and coronal section in T1-weighted and diffusion sequences of a malignant tumor of the right parotid.

Table 1: Histological distribution of parotid tumors.

\begin{tabular}{|c|c|}
\hline Benign Tumors & 38 \\
\hline Pleomorphic adenoma & 23 \\
\hline Whartin tumors & 7 \\
\hline Basal cell adenoma & 2 \\
\hline Myoepithelioma & 1 \\
\hline Lipoma & 1 \\
\hline Neurofibroma & 1 \\
\hline Cyst & 1 \\
\hline Oncocytoma & 1 \\
\hline Solitary fibrous tumor & 1 \\
\hline
\end{tabular}




\begin{tabular}{|c|l|}
\hline & Malignant Neoplasms \\
\hline Mucoepidermoid carcinoma & 2 \\
\hline Squamous cell carcinoma & 2 \\
\hline Carcinoma on pleomorphic adenoma & 2 \\
\hline Rhabdomyosarcoma & 1 \\
\hline Undifferentiated carcinoma & 1 \\
\hline
\end{tabular}

The Association: Low signal intensity on T1, high signal intensity on $\mathrm{T} 2$, apparent diffusion coefficient superior to 1,5 and positive enhancement after injection of contrast product, was significant in predicting the histological diagnosis of pleomorphic adenoma, with a specificity $100 \%$ of and a sensibility of $83 \%$. The association: low signal intensity on $\mathrm{T} 1$, irregular lesion limits, apparent diffusion coefficient inferior to 1 and extra parotid extension, was significant in predicting the histological diagnosis of malignant tumors with a specificity of $100 \%$ and a sensibility of $67 \%$. However no statistically significant association was found for the cases of warthin tumors. The MRI histological correlation predicting the benignity or malignancy of the parotid tumor showed that for a total of 39 MRI results, the correlation was statistically significant $(\mathrm{p}<0.001)$ with a sensibility of $100 \%$ and specificity of $94,1 \%$. Furthermore, the MRI histological correlation predicting the diagnosis of pleomorphic adenoma was statistically significant ( $p<0.001$ ) with a sensibility of $90 \%$ and specificity of $86,7 \%$.

\section{Discussion}

MRI currently appears to be the preferred examination in the exploration of the tumor pathology of the parotid glands, possibly combined with fine needle aspiration [2]. It is a noninvasive examination, allowing reconstruction in all planes and excellent tissue discrimination, however it is not tolerated by all patients, in particular claustrophobic ones, and its duration of acquisition remains significant with a weak bone characterization. Nevertheless, MRI is considered superior to computed tomography for the detection and analysis of a parotid tumor process. In clinical practice, the first step is to affirm an intraparotid tumor process. The ultrasound of the parotid region is a rapid, accessible, noninvasive examination allowing good diagnostic sensitivity, with the possibility of acquisition in all planes. On the other hand, it is operator-dependent and offers poor accessibility for deep structures. Its sensitivity, specificity and relevance to tumors are 62, 91 and 85\% respectively [3]. Some studies have analyzed the contribution of scintigraphy to 18-fluorodeoxyglucose. This examination does not seem to offer sufficient information for parotid tumor detection, even in image fusion with computed tomography [4].

The second step is to confirm the parotid origin of a large tumor or a tumor with a deep location. Three criteria allow MRI to confirm the parotid origin of the lesion: the medial displacement of the parapharyngeal fat; the lateral center of mass, relative to the parapharyngeal space; and the widening of the distance between the styloid process and the mandibular angle at the front [4]. During this stage, the needle aspiration is also discussed: some authors give relevance figures reaching 97\% [5,6], others are more reserved obtaining lower results [7]. Some complications are possible such as a hematoma, facial paralysis [8] or even the implantation, however exceptional, on the puncture pathway of malignant tumor cells [9]. In all cases, this examination is highly operator dependent. The third step is to distinguish a benign tumor from a malignant one. The literature review made it possible to objectify studies of correlations between MRI and histological results in parotid tumors, the results of which were close to those found in our study. A study by A Khalek Abdel Razek et al. published in 2019 [10] objectified the presence of a correlation between the diffusion coefficient and the histological grade of parotid malignancies with as main points:

a) Low $\mathrm{ADC}$ values are correlated with advanced $\mathrm{T}$ stages of parotid tumors

b) $\mathrm{ADC}$ values for cancers with N3 N2 lymph node status are lower than those for cancers with N0 N1 status.

c) An inverse correlation between $\mathrm{ADC}$ values and the degree of tumor differentiation: lower ADC for high grade tumors.

Another study conducted by A Elmokadem et al. in 2019 [11] allowed the multi-parameter analysis of MRI to differentiate benign tumors from malignant tumors and concluded that:

1) Presence of a significant difference in the location of benign tumors (predominant in the superficial lobe) and malignant tumors, and in the study of the perfusion signal with predominance of type $\mathrm{A}$ and $\mathrm{B}$ curve for benign tumors and $\mathrm{C}$ for tumors malignant.

2) No statistically significant difference between benign and malignant tumors regarding ADC values. AT. Christe et al. conducted a study [12] on MRI characteristics for differentiation between benign and malignant tumors and found a sensitivity of $70 \%$ and a specificity of $73 \%$ of malignancy for low signal intensity on T2 lesions with irregular limits [13-15].

d) A study by J Prades et al. [16] established in 68 patients, with an average age of 51 years, 30 pleomorphic adenomas with the following values concerning the specificity and sensitivity of MRI (Table 2). 
Table 2: Predictive diagnostic values of MRI for parotid tumors.

\begin{tabular}{|c|c|c|c|}
\hline & Sensibility & Our Study & Our Study \\
\hline Pleomorphic Adenoma & 87,5 & 83 & 80,5 \\
\hline Whartin Tumor & 45,5 & & 93,3 \\
\hline Malignant Tumor & 75,0 & 67 & 96,2 \\
\hline
\end{tabular}

\section{Conclusion}

MRI is currently the first line examination for the detection of a tumor in the parotid gland. It provides excellent spatial resolution and relevant tissue discrimination. It also makes it possible to confirm or deny a surgical indication for parotidectomy. Based on morphological and functional arguments, it gives a very specific diagnostic orientation to the anatomopathological results found in postoperative.

\section{References}

1. M Fassih, I Layla, A Abada (2010) Parotid tumors: Epidemiological and clinical study and contribution of imagery to diagnosis. Moroccan journal of cancer $4: 45-50$.

2. Goto TK, Yoshiura K, Nakayama E, Youasa K, Tabata O, et al. (2001) The combined use of US and MR imaging for the diagnosis of masses in the parotid region. Acta Radiol 42(1): 88-95.

3. Suzuki H, Takeuchi Y, Numata T, Tsukuda T, Shimada F, et al. (1997) Ultrasonographic diagnosis of the parotid gland tumors, experience with 310 patients. Nippon Jibiinkoka Gakkai Kaiho 100(9): 893-899.

4. Joe VQ Westesson P (1994) Tumors of the parotid gland: MR imaging characteristics of various histologic types. AJR 163(2): 433-438.

5. Lampe HB, Savoury L, Nicholson RL, Heenman H, Yakemchuk G (1988) Evaluation of parotid lesions by magnetic resonance imaging. J Otolaryngol 17(4): 183-186.

6. Young Liang W, Siu Cheung C, Yao Liang C (2004) Ultrasonographyguided core-needle biopsy of parotid gland masses. AJNR Am J Neuroradiol 25(9): 1608-1612.

7. Balakrishnan K, Castelling B, Mc Mahon J, Imrie J, Feeley KM, et al. (2005) Fine needle aspiration cytology in the management of a parotid mass: a two centre retrospective study. Surgeon 3(2): 67-72.

ISSN: 2574-1241

DOI: $10.26717 /$ BJSTR.2020.27.004525

Z Alj. Biomed J Sci \& Tech Res

(C) This work is licensed under Creative

Submission Link: https://biomedres.us/submit-manuscript.php
8. Buckland JR, Manjaly G, Violaris N, Howlett DC (1999) Ultrasound guided cutting-needle biopsy of the parotid gland. J Laryngol Otol 113(11): 988992.

9. Yamaguchi KT, Strong MS, Shapshay SM, Soto E (1979) Seeding of parotid carcinoma along Vim-Silverman needle tract. J Otolaryngol 8(1): 49-52.

10. A Khalek Abdel Razek, SM Elkhamary, N Nada (2019) Correlation of apparent diffusion coefficient with histopathological parameters of salivary gland cancer. Int J Oral Maxillofac Surg 48(8): 995-1000.

11. Ali H Elmokadem, Ahmed M Abdel Khalek, Rihame M Abdel Wahab, N Tharwat, Gaballa GM, et al. (2019) Diagnostic Accuracy of Multiparametric Magnetic Resonance Imaging for Differentiation Between Parotid Neoplasms. Canadian Association of Radiologists Journal 70(3): 264-272.

12. Christe A, Waldherr C, Hallett R, Zbaeren P, Thoeny H (2011) MR Imaging of Parotid Tumors: Typical Lesion Characteristics in MR Imaging Improve Discrimination between Benign and Malignant Disease. AJNR 32(7): 1202-1207.

13. Divi V, Fatt MA, Teknos TN, Mukherji SK (2005) Use of cross-sectional imaging in predicting surgical location of parotid neoplasms. J Comput Assist Tomogr 29(3): 315-319.

14. Yousem DM, Kraut MA, Chalian AA (2000) Major salivary gland imaging. Radiology 216(1): 19-29.

15. Habermann CR, Gossrau P, Graessner J, C Arndt, M C Cramer, et al. (2005) Diffusion-weighted echo-planar MRI: a valuable tool for differentiating primary parotid gland tumors. Rofo 177(7): 940-945.

16. Prades JM, Oletski A, Faye MB, Dumollard JM, Timoshenko AP, et al. (2007) Parotid gland masses: diagnostic value of MR imaging with histopathologic correlations. Morphologie 91(292): 44-51.

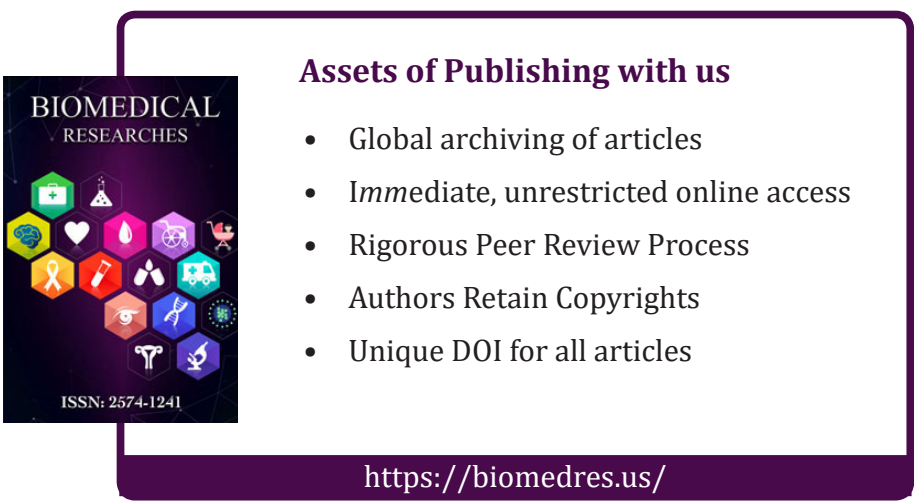

